\title{
PUSH OUT BOND STRENGTH OF ROOT CANAL FILLING WITH EPOXY RESIN-BASED, MTA-BASED AND BIOCERAMIC-BASED ENDODONTIC SEALERS
}

\author{
Soliman M. Kamha * and Howida A. Enan **
}

\begin{abstract}
Aim: to compare the push out bond strength of the root canal filling with epoxy resin-based (Adseal), MTA-based (MTA Fillapex) and Bioceramic-based (Endosequance BC) sealers.

Materials and Methods: Forty five extracted mandibular human first premolars with straight fully formed roots were selected for this study and were de-coronated at $17 \mathrm{~mm}$ from the apex. All root canals were prepared by using the ProTaper Universal Ni Ti rotary system in a crown down manner up to F4 according to manufacturer's instruction to the their working length. The canals were irrigated with $17 \%$ EDTA to remove the smear layer and the final rinse was performed with $5 \mathrm{~mL} 5.25 \%$ sodium hypochlorite. The roots were randomly assigned to three groups, fifteen for each $(n=15)$. Adseal, MTA Fillapex and Endosequence BC sealers were used with gutta percha size F4 by lateral condensation technique for groups I, II and III respectively. All roots stored in $100 \%$ humidity at $37^{\circ} \mathrm{C}$ for one week for completing setting of sealers. The roots were embedded in self cure acrylic resin, and transversely sectioned perpendicular to the long axis of the root 2 $\mathrm{mm}$ thickness slices. Apical diameter of $0.88 \pm 0.02 \mathrm{~mm}$ in all slices were selected for the pushout test by universal testing machine. The dislodging force was measured in Newton for all slice samples and tabulated. Push out bond strength (MPa) for every slice sample is calculated and the three groups were compared. The slices were then examined under stereomicroscope and categorized into adhesive, cohesive or mixed type of bond failure mode. The data were tabulated and statistically analyzed.
\end{abstract}

Results: Endosequence bioceramic represented the highest bond strength followed by Adseal then MTA Fillapex which represented the lowest bond strength with a significant difference between them at $\mathrm{P} \leq 0.05$. Comparison between Adseal and Endosequence bioceramic groups and between MTA Fillapex and Endosequence bioceramic groups showed a significant difference between them at $\mathrm{P} \leq 0.05$ with higher bond strength of Endosequence bioceramic sealer. Adseal represented higher bond strength than MTA Fillapex with no significant difference between them at $\mathrm{P} \leq 0.05$. Comparison between the three tested groups of sealers regarding the bond failure categories showed no significant difference between them at $\mathrm{P} \leq 0.05$.

* Lecturer of Endodontics, Faculty of Dentistry, Pharos University

** Demonstrator of Endodontics, Faculty of Dentistry, Pharos University 
Conclusion: Within the limitations of this study, Endosequence bioceramic sealer show promising results as root canal sealer and exhibited a greater resistance to push out than MTA Fillapex and epoxy resin-based sealer (Adseal) with gutta-percha as a root canal filling.

KEYWORDS: Push out test, bond strength, universal testing machine, epoxy resin sealer, Adseal sealer, MTA Fillapex sealer, Endosequance bioceramic sealer

\section{INTRODUCTION}

Successful endodontic therapy consists of shaping and cleaning the root canal system and sealing the intracanal space with a hermetic 3-dimensional filling to avoid leakage from the oral cavity and/or periapical tissues ${ }^{[1]}$. Therefore, it prevents further apical irritation from either incomplete elimination of bacteria and their products or communication between apical tissues and oral cavity, thereby reducing periapical inflammation ${ }^{[2,3]}$.

Gutta-percha, is considered as a standard procedure in endodontic obturation. It is widely used for its good physical and biological properties with lack of adhesiveness and flow to the dentin surface, makes the combination with endodontic sealers necessary ${ }^{[4]}$.

The root canal sealer should have adequate flow for filling gaps between gutta-percha cones and the canal walls and bond strength to root dentin, which will contribute to the quality of sealing ${ }^{[1,5]}$. Moreover, during mechanical preparation of the post space, root canal filling material might be dislodged, creating voids in the obturation that will affect the quality of the apical seal ${ }^{[6-9]}$. Sealers which can adhere to the root canal dentin surface will strengthen the remaining tooth structure, thereby contributing to the long-term success of an endodontically treated tooth ${ }^{[10,11]}$.

Differences in the adhesive properties of endodontic sealers may be due to their interaction with either dentin or gutta-percha which may vary with their chemical composition ${ }^{[12]}$. Surface tension of the sealers, surface energy of the dentin or core materials, differences in thermal expansion coefficients and dimensional changes during setting of endodontic sealers may affect adhesive bonds ${ }^{[13]}$. Also, endodontic sealers should have a sufficient setting time, insolubility against tissue fluids, dimensional stability, and biocompatibility ${ }^{[14,15]}$.

Sealing ability of the endodontic sealers has improved through the mechanical interlocking of the sealer plug inside the dentinal tubules following smear layer removal ${ }^{[16,17]}$. Lalh et al $(1990)^{[18]}$ found that the bond strength of some sealer cements to dentin was better in the presence of smear layer which might act as a coupling agent, thereby improving the adaptation of hydrophilic materials to the root canal wall ${ }^{[19]}$.

There were many types of sealers introduced, zinc oxide-eugenol cements ${ }^{[20]}$, epoxy resin-based sealers ${ }^{[21]}$, calcium hydroxide-based sealers ${ }^{[22]}$, and glass ionomer-based sealers ${ }^{[23]}$.

Adseal (Meta, Biodent, Korea) is an epoxy resinbased sealer supplied in a paste-paste type of dual syringe. It has extremely excellent sealing property and biocompatibility. It gave the highest bond strength of all sealers tested to both dentin and guttapercha through its ability to react with any exposed amino groups in collagen to form covalent bonds between the resin and collagen when the epoxide ring opens ${ }^{[24,25]}$. This bond is maintained by low polymerization stress, long-term dimensional stability, and efficient cohesion between molecules ${ }^{[13,24,26]}$.

Recently, MTA Fillapex (Angelus, Londrina, PR, Brazil) is MTA-based sealer presented in a paste-paste system and composed of resins, bismuth oxide, silica nanoparticles, and pigments. It is a modification of the MTA original formulations to improve the characteristics such as good radiopacity, flow, setting time, alkaline $\mathrm{pH}$ and adhesion, 
allowing their use as endodontic sealers ${ }^{[27-31]}$. Sealing capacity is largely attributed to bioactivity of MTA and its ability to release calcium ions and produce an apatite layer in the presence of phosphate containing physiological fluids which influence the push-out bond strength of MTA ${ }^{[32-35]}$.

More recent, Endosequence BC sealer (Brasseler USA, Savannah, GA) is a new bioceramic root canal sealer. It is a premixed and injectable endodontic sealer, and its nanoparticle size allows it to flow readily into canal irregularities and dentinal tubules. It is an insoluble, radiopaque and aluminum free material based on a calcium silicate composition. It is hydrophilic and uses moisture in dentinal tubules to initiate and complete its setting reaction with no shrinkage resulting in a gap-free interface between the gutta-percha, sealer, and dentin ${ }^{[36]}$. Also, it is highly biocompatible and is antibacterial during the setting reaction because of its highly alkaline $\mathrm{pH}^{[37,38]}$.

Bond-strength testing methods are used for determining the effectiveness of adhesion between endodontic materials and tooth structure ${ }^{[39]}$. The most common are the tensile and shear bond strength testing. Test designed to measure shear bond strength includes the planar interface shear test and push-out test. Regarding push-out test, the force required to dislodge the test material when pushed out of the root canal is evaluated ${ }^{[40]}$.

Therefore, this in-vitro study was done to evaluate the bond strength of the three types of root canal sealers, Adseal, MTA Fillapex, and EndoSequence BC sealer using push-out test and to assess the failure modes on the debonded surfaces by stereomicroscope.

\section{MATERIALS AND METHODS}

\section{Selection of samples}

Forty five extracted mandibular human first premolars with straight fully formed roots were obtained from the tooth bank of Pharos University and stored in saline until use. Teeth with more than one canal, open apex, endodontically treated, Internal or external resorption, caries, cracks or fractures on the root surfaces were excluded from this study.

\section{Preparation of samples}

Preoperative mesiodistal and buccolingual radiographs of each tooth were taken to confirm the singular canal anatomy and absence of internal resorption. All samples were cleaned using curettes and immersed in 5.25\% sodium hypochlorite for 10 minutes to remove the hard and soft tissues respectively and stored in distilled water until use.

Teeth were de-coroneted at $17 \mathrm{~mm}$ root length from the apex, using a low-speed hand piece with a diamond disc under continuous water irrigation (Figure 1). A size 10 K-type file (Dentsply / Sirona, Ballaigues, Switzerland), was passively advanced into the canals until the tip of the instrument penetrated and adjusted to the apical foramen. The real canal length was recorded, and the working length (WL) was calculated by subtracting $1 \mathrm{~mm}$ from this measurement.

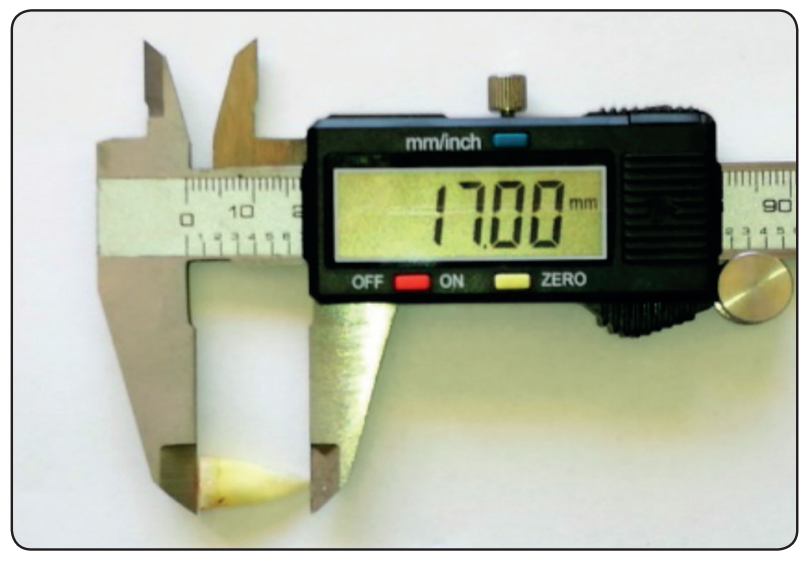

Fig. (1) De-coroneted tooth at $17 \mathrm{~mm}$ root length from the apex. 


\section{Canal Preparation}

The glide path was created for every root canal with proGlider (size 16, 2\% apical taper) (Dentsply / Sirona, Switzerland) to ensure more safety during the use of the first NiTi rotary file. All root canals were prepared by using the ProTaper Universal NiTi rotary system (Dentsply/ Sirona, Switzerland) in a crown down manner with a torque controlled engine (X-Smart, Dentsply, UK) at $250 \mathrm{rpm}$ according to manufacturer's instruction. Instrumentation started with Shaping Files (SX, S1, and S2) then finishing files (F1, F2, F3, and F4) to the working length.

Canal patency was checked with a size $10 \mathrm{~K}$-file (Dentsply/ Sirona, Switzerland) between every file used $1 \mathrm{~mm}$ beyond the apical foramen.

During instrumentation, the root canals were irrigated with $5.25 \%$ sodium hypochlorite between files. Chelating gel "Glide" (Dentsply) was used with all files. All instruments were discarded after being used in 5 root canals, and all canals were prepared by the same operator.

At the end of the preparation, the apical size was verified with size 40 st.st. $\mathrm{K}$ file.

The canal was irrigated with $3 \mathrm{~mL}$ 17\% EDTA (Diadent, Korea) for 3 minutes to remove the smear layer. The final rinse was performed with $5 \mathrm{~mL}$ $5.25 \%$ sodium hypochlorite.

\section{Canal Obturation}

The master gutta percha cone whose diameter was the same as that of master apical file with tugback feeling inside every root canal was selected (\# F4). The master gutta percha cone was notched at the working distance analogous to the level of the occlusal reference point. Then it was verified by radiograph.

The size of root canal spreader to be used for lateral compaction was selected according to the size of master cone. It should reach 1 to $2 \mathrm{~mm}$ of true working length. The root canals were dried with sterile paper points and the sealer was applied into the prepared root canals according to the type of root canal sealer for each group.

\section{Grouping}

The roots were randomly assigned to three groups according to the root canal sealer used.

\section{Group I}

Fifteen roots obturated with gutta purcha cones size F4 and Adseal (Meta, Biomed, Korea) root canal sealer using lateral condensation technique. This type of sealer is an epoxy resin based root canal sealer which is a paste-paste (Base and Catalyst) type of dual syringe delivered on a mixing pad and spatulated for 15-20 seconds or until creamy homogeneous consistency.

\section{Group II}

Fifteen roots obturated with gutta purcha cones size F4 and MTA Fillapex (Angelus/ Londrina, Brasil) root canal sealer using lateral condensation technique. This type of sealer introduced in the form of two tubes, base and catalyst pastes. The two equal volumes of pastes (1:1) were mixed for 30 seconds to a homogeneous consistency and inserted to the canal by coating the master cone with a thin layer of sealer.

\section{Group III}

Fifteen roots obturated with gutta purcha cones size F4 and Endosequence bioceramic (Basselar Boulevard/ Georgia, USA) root canal sealer using lateral condensation technique. This type of sealer is a premixed ready to use injectable bioceramic paste developed for permanent root canal filling and sealing applications. It is packaged in a pre-loaded syringe and is supplied with disposable BC tips. It may be delivered into the canal via the tips provided or it can be delivered via traditional methods by coating the master cone with a thin layer of sealer.

The premeasured master cone was coated with sealer and placed inside the root canal to its notch in relation to the occlusal reference point after cutting $1 \mathrm{~mm}$ from its tip by sharp scalpel. The selected 
spreader was placed into the root canal alongside the master cone with apical pressure to 1 to $2 \mathrm{~mm}$ of the working length. It acted as a wedge to squeeze the gutta percha cone laterally. The spreader was removed from the root canal by rotating it back and forth leaving a space lateral to the master cone. The accessory gutta pecha cone was coated with sealer and placed in this space. The above procedure was repeated until the spreader could no longer penetrate the root canal.

After verifying the obturation by radiograph, the protruded gutta percha points were severed at the root canal orifice with a hot instrument and compacted apically with a large plugger to seal the root canal orifice with soft gutta-percha.

All samples of the three groups were radiographed in bucco-lingual and mesio-distal directions to confirm the quality of the root canal obturation and stored in $100 \%$ humidity at $37^{\circ} \mathrm{C}$ for one week for complete setting of sealer.

\section{Preparation of samples for push out test}

The roots were embedded in self cure acrylic resin, centralized in standardized tubes (Figure 2). Thereafter, the samples were transversely sectioned perpendicular to the long axis of the root $2 \mathrm{~mm}$ thickness slices with diamond discs under copious water irrigation to avoid deformation of the obturating materials (Figure 3).

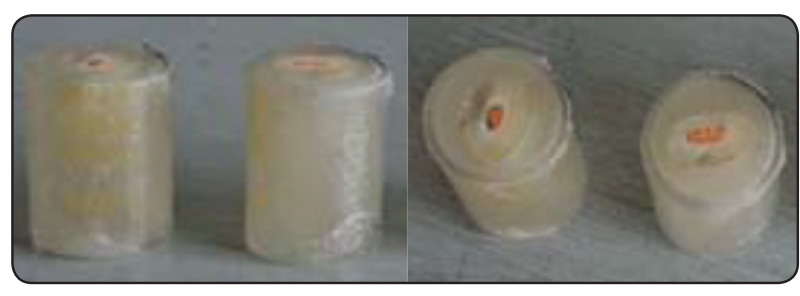

Fig. (2) Roots embedded in self cure acrylic resin, centralized in standardized tubes.

A digital caliper was used to measure the coronal and apical diameters and select the slices which the apical diameter is $0.88 \pm 0.02 \mathrm{~mm}$ for the push-out test. Special marker was used to mark the apical area of the slice samples.

\section{Push out test}

A cylindrical stainless steel plunger of $0.8 \mathrm{~mm}$ diameter was set up in the upper part of a universal testing machine (Comten industries Inc, Petersburg, Florida, USA). The slice samples were seated in the lower part of the testing machine with the apical face directed upward. Loading was performed on a universal testing machine over the tested filling material and avoiding touching the surrounding dentin wall at a head-speed of $0.5 \mathrm{~mm} / \mathrm{min}$ until dislodging of the material occurred. The load was applied only in an apico-coronal direction. The dislodging force (maximum load) was measured in Newton for all slice samples and tabulated (Figure 4).

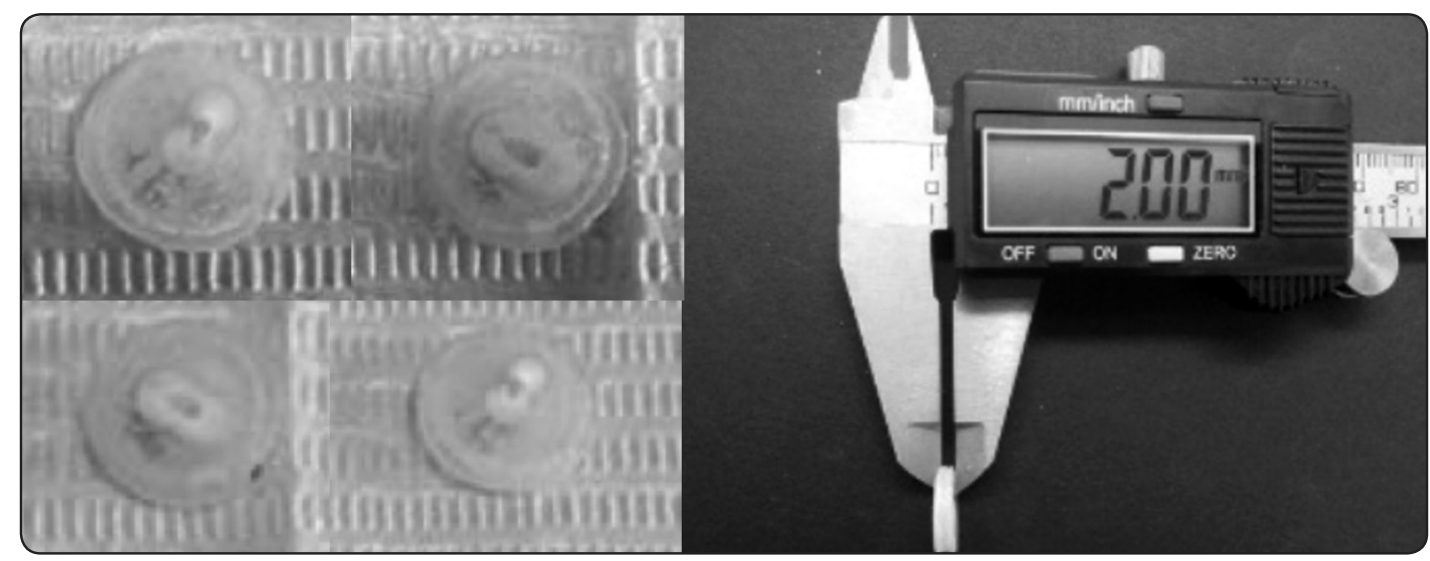

Fig. (3): Transversely sectioned roots embedded in self cure acrylic resin with $2 \mathrm{~mm}$ thickness slices. 


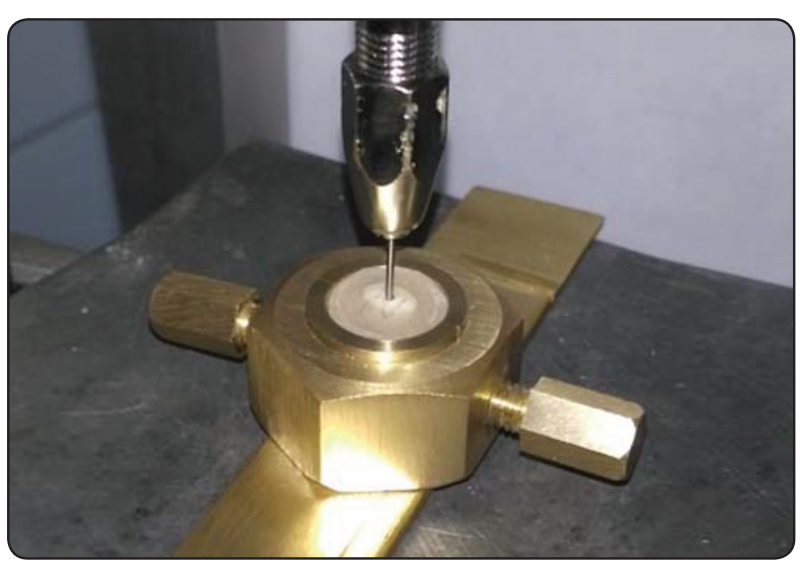

Fig. (4): Slice sample seated in the lower part of the testing machine and a cylindrical stainless steel plunger of 0.8 $\mathrm{mm}$ diameter in the upper part.

Push out bond strength (MPa) for every slice sample is equal to Maximum load (N)/ Adhesion surface area ${ }^{[41]}$

Calculation of the adhesion area was carried out through the following formula:

$(\mathrm{R}+\mathrm{r})\left[\mathrm{h}^{2}+(\mathrm{R}-\mathrm{r})^{2}\right]^{0.5}$ where and $\mathrm{R}, \mathrm{r}$, and $\mathrm{h}$ indicate the coronal and apical radii and slice thickness, respectively.

\section{Failure mode}

The slices were then examined under stereomicroscope (Olympus SZ 1145 TR, Tokyo, Japan, and Mag.110 X) and digital micrographic images with their numbers were captured and saved to determine the nature of bond failure. Each sample was categorized into one of three failure mode ${ }^{[42]}$ :

1- Adhesive failure, at the sealer and dentin interface

2- Cohesive failure, within the obturating material (gutta percha and sealer)

3- Mixed failure, where the sample showed both adhesive and cohesive failure.

The data were tabulated and statistically analyzed.

\section{Statistical analysis of the data}

Data were fed to the computer and analyzed using IBM SPSS software package version 20.0. Comparisons between groups for categorical variables were described using number and percent and were assessed using Chi-square test. Normally quantitative data was expressed as Mean \pm SD and compared using F-test (ANOVA) and Post Hoc test (Tukey) for pairwise comparisons. Significance of the obtained results was judged at the $5 \%$ level.

\section{RESULTS}

Push out bond strength of Adseal, MTA Fillapex and Endosequence bioceramic sealers were determined by the following formula:

Push out bond strength $(\mathrm{MPa})=$ Maximum load $(\mathrm{N}) /$ Adhesion surface area which is equal to $(\mathrm{R}+$ r) $\left[h^{2}+(R-r)^{2}\right]^{0.5}$ where and $R, r$, and $h$ indicate the coronal and apical radii and slice thickness, respectively.

The mean \pm slandered deviation valves of push out bond strength were equal to $44.1 \pm 16.3,33.3 \pm$ 10.1, and 123.1 \pm 48.1 in Adseal, MTA Fillapex and Endosequence bioceramic groups respectively.

Comparison between the three groups of sealers, Endosequence bioceramic represented the highest bond strength followed by Adseal and MTA Fillapex represented the lowest bond strength with a significant difference between them at $\mathrm{P} \leq 0.05$.

Comparison between Adseal and Endosequence bioceramic groups, Endosequence bioceramic represented higher bond strength than Adseal with a significant difference between them at $\mathrm{P} \leq 0.05$.

Comparison between MTA Fillapex and Endosequence bioceramic groups, Endosequence bioceramic represented higher bond strength than MTA Fillapex with a significant difference between them at $\mathrm{P} \leq 0.05$.

Comparison between Adseal and MTA Fillapex groups, Adseal represented higher bond strength than MTA Fillapex with no significant difference between them at $\mathrm{P} \leq 0.05$. (Table 1) (Figure 5) 
TABLE (1) Comparison between mean \pm standard deviation values of push out bond strength (MPa) for Adseal, MTA Fillapex and Endosequence bioceramic sealers.

\begin{tabular}{|c|c|c|c|c|c|}
\hline & $\begin{array}{c}\text { Adseal } \\
(\mathbf{n = 1 5})\end{array}$ & $\begin{array}{c}\text { MTA } \\
(\mathbf{n = 1 5})\end{array}$ & $\begin{array}{c}\text { Endosequence } \\
\text { bioceramic } \\
(\mathbf{n = 1 5})\end{array}$ & $\mathbf{F}$ \\
\hline $\begin{array}{c}\text { Push out bond strength } \\
\text { (mean } \pm \text { SD) }\end{array}$ & $44.1 \pm 16.3$ & $33.3 \pm 10.1$ & $123.1 \pm 48.1$ & $40.417^{*}$ & $<0.001^{*}$ \\
\hline Sig. bet. grps & \multicolumn{2}{|c|}{$\mathrm{p}_{1}=0.589, \mathrm{p}_{2}<0.001^{*}, \mathrm{p}_{3}<0.001^{*}$} \\
\hline
\end{tabular}

Normally quantitative data was expressed in mean \pm SD and was compared using F test ANOVA, Sig. bet. grps was done using Post Hoc Test (Tukey)

$p_{l}:$ p value for comparing between Adseal and MTA

$p_{3}$ : $p$ value for comparing between MTA and Bioceramic

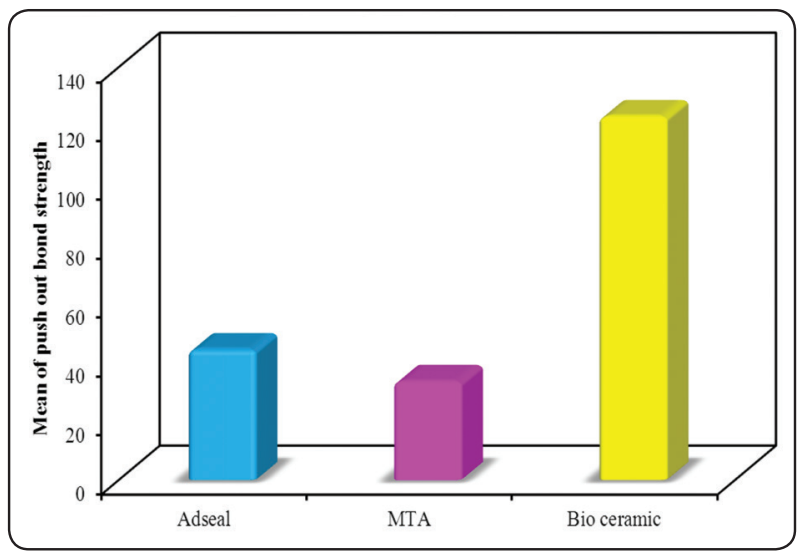

Fig. (5): Comparison between mean \pm standard deviation values of push out bond strength (MPa) for Adseal, MTA Fillapex and Endosequence bioceramic sealers.

Failure mode of slice samples was categorized into one of the following:

1. Adhesive failure, at the sealer and dentin interface

2. Cohesive failure, within the obturating material (gutta percha and sealer) $p_{2}: p$ value for comparing between Adseal and Bioceramic *: Statistically significant at $p \leq 0.05$

3. Mixed failure, where the sample showed both adhesive and cohesive failure.

Adhesive failure was recorded in $5(33.3 \%)$, $6(40.0 \%)$ and $6(40.0 \%)$ slices in Adseal, MTA Fillapex and Endosequence groups respectively. Comparison between the three groups regarding to adhesive failure revealed no significant difference between them at $\mathrm{P} \leq 0.05$.

Cohesive failure was recorded in 4 (26.7\%), $2(13.3 \%)$ and $0(0.0 \%)$ slices in Adseal, MTA Fillapex and Endosequence groups respectively. Comparison between the three groups regarding to Cohesive failure revealed no significant difference between them at $\mathrm{P} \leq 0.05$.

Mixed failure,Adhesive failure / Cohesive failure, was recorded in $6(40.0 \%), 7$ (46.7\%) and $9(60.0 \%)$ slices in Adseal, MTA Fillapex and Endosequence groups respectively. Comparison between the three groups regarding to Mixed failure, Adhesive failure / Cohesive failure, revealed no significant difference between them at $\mathrm{P} \leq 0.05$. (Table 2) (Figure 6) 
TABLE (2) Comparison between numbers and percentages of samples of Adseal, MTA Fillapex and Endosequence bioceramic sealers according debonding interface

\begin{tabular}{|c|c|c|c|c|c|}
\hline $\begin{array}{c}\text { Debonding } \\
\text { interface }\end{array}$ & $\begin{array}{c}\text { Adseal } \\
(\mathbf{n = 1 5})\end{array}$ & $\begin{array}{c}\text { MTA Fillapex } \\
(\mathbf{n = 1 5})\end{array}$ & $\begin{array}{c}\text { Endosequence bioceramic } \\
(\mathbf{n = 1 5})\end{array}$ & $\mathbf{c}^{2}$ & $\mathbf{p}$ \\
\hline Adhesion & $5(33.3 \%)$ & $6(40.0 \%)$ & $6(40.0 \%)$ & 0.189 & 0.910 \\
\hline Mixed & $6(40.0 \%)$ & $7(46.7 \%)$ & $9(60.0 \%)$ & 1.245 & 0.537 \\
\hline Cohesion & $4(26.7 \%)$ & $2(13.3 \%)$ & $0(0.0 \%)$ & 4.403 & 0.145 \\
\hline
\end{tabular}

$c 2, p: c 2$ and $p$ values for Chi square test for comparing between the three groups

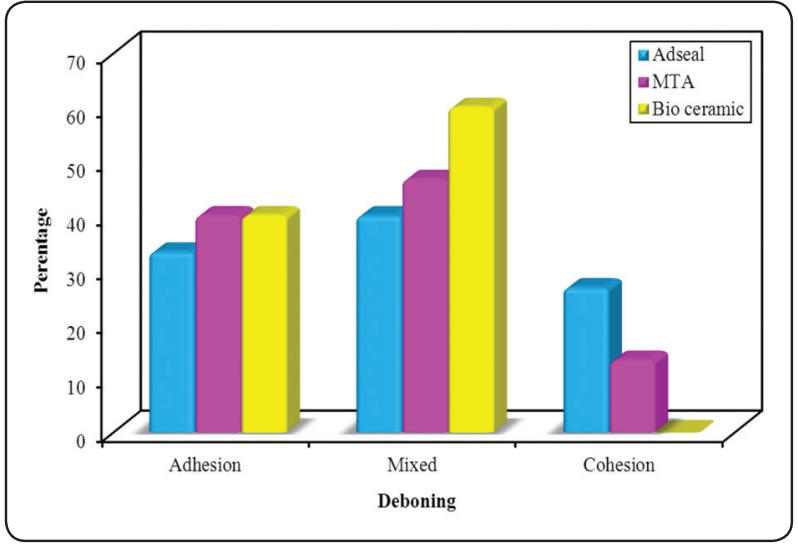

Fig. (6): Comparison between numbers and percentages of samples of Adseal, MTA Fillapex and Endosequence bioceramic sealers according debonding interface

\section{DISCUSSION}

The main objective of endodontic treatment after completing the chemo-mechanical preparation is to get a 3D obturation of the root canal system space with hermetic seal.

Because of the poor adhesiveness of gutta-percha, root canal sealers must be used to fill imperfections and increase adaptation of the root filling material to the canal walls to avoid any chance for leakage and failure ${ }^{[43-46]}$.

Adhesion of root canal sealer is necessary to avoid its dislocation because of tooth flexure, operative procedures, or post space preparation. The push-out test is commonly used to evaluate bond strength between sealer and canal walls ${ }^{[47,48]}$.
In the present study, epoxy resin-based sealer (Adseal), MTA-based sealer (MTA Fillapex) and Endosequence Bioceramic sealer were compared regarding to their push out bond strength. It was found that, Endosequence Bioceramic sealer showed the highest bond strength followed by the epoxy resin-based sealer (Adseal) and the lowest one was MTA-based sealer (MTA Fillapex) with a significant difference between them. This result was in agreement with Gade et al (2015) ${ }^{[49]}$ and Kumar et al (2016) ${ }^{[50]}$ who found that, Endosequence BC Sealer showed the highest bond strength than the same types of sealers used in our study which may be due to formation of a chemical bond (through production of hydroxyapatite during setting) with dentine and its hydrophilic property helping in spreading easily over the canal walls providing adaptation and good hermetic seal.

In the current study, comparison between epoxy resin-based sealer (Adseal) and Endosequence Bioceramic sealer revealed higher bond strength of bioceramic sealer with a significant difference between them which is in agreement with Mahdi et al (2013) [51] who found that, epoxy resinbased sealer, shows good bond strength next to Endosequence. But, this result was in contrast to Koch and Brave (2009) ${ }^{[52]}$ who stated that, in most studies, Endosequence sealer were equivalent to epoxy resin-based sealers, which are known by its excellent bonding properties ${ }^{[53]}$. Also, this result was in disagreement with Shokouhinejad et al (2013) 
[42] who found no significant difference between the bond strength of gutta percha/ AH Plus (epoxy resin-based) and gutta-percha/EndoSequence BC Sealer.

In the present study, comparison between MTA Fillapex and Endosequence bioceramic groups, Endosequence bioceramic represented higher bond strength than MTA Fillapex with a significant difference between them which was similar to the conclusion of DeLong et al (2015) ${ }^{[43]}$.

Comparison between Adseal and MTA Fillapex groups in this study, Adseal represented higher bond strength than MTA Fillapex with no significant difference between them. This result was in agreement with Yavari et al (2017) ${ }^{[41]}$ who concluded that, AH Plus sealer exhibited a higher bond strength compared to MTA Fillapex. The higher values of bond strength associated with epoxy resin sealers have been ascribed to the covalent bond between epoxide (open circle) and the exposed amino groups in collagen, very low shrinkage while setting, and long-term dimensional stability ${ }^{[13,54,55,56]}$. The bonding behaviors of MTA-based sealers can be affected by their chemical compositions through the presence of resin components in its structure ${ }^{[13,31,57]}$. According to the results obtained by Borges et al (2012) ${ }^{[58]}$ and Nagas et al (2012) ${ }^{[59]}$, the bond strength differences of MTA Fillapex and AH Plus sealers can be attributed to the much higher solubility of MTA Fillapex sealer. But, it was in contrast to Assmann et al (2012) ${ }^{[60]}$ who concluded that, MTA Fillapex presented acceptable resistance to dislodgement, which was similar to that observed in samples filled with AH epoxy resin sealer.

In the present study, failure mode of slice samples was categorized into adhesive, cohesive or mixed failure. Comparison between Adseal, MTA Fillapex and Endosequence bioceramic groups revealed no significant difference regarding the three types of bond failure.

In Adseal group, the bond failed in 33.3\%, 40\% and $26.7 \%$ and in MTA Fillapex group the bond failed in $40 \%, 46.7 \%$ and $13.3 \%$ of the specimens as regard the adhesive, mixed and cohesive failure respectively which was in contrast to Assmann et al (2012) ${ }^{[60]}$ who found that, all slices of MTA Fillapex and AH Plus specimens studied failed at the sealer/ dentin interface (adhesive failure).

In Endosequence bioceramic group, the bond failed in $40 \%, 60 \%$ and $0 \%$ of the specimens as regard the adhesive, mixed and cohesive failure respectively which was in contrast to Huffman et al. (2009) ${ }^{[53]}$ who showed that, the failure mode for a calcium silicate-based sealer was cohesive after a 7 day storage period and also disagree with Eldeniz et al (2005) ${ }^{[61]}$ who found that, the failure mode appeared to be predominantly cohesive within the sealer for AH Plus in the presence or absence of smear layer. Moreover, Gesi et al. (2005) ${ }^{[62]}$ showed that, the mode of bond failure was mostly cohesive within the filling material in root canals filled with gutta-percha/AH Plus.

The present study showed that, any of the EndoSequence BC specimens revealed cohesive bond failure which in contrast to Shokouhinejad et al (2013) ${ }^{[42]}$ who inspected samples filled with gutta percha/ AH Plus and gutta-percha/ EndoSequence $\mathrm{BC}$ Sealer and found that, the type of bond failure was mainly cohesive for all groups.

\section{CONCLUSION}

Within the limitations of this study, Endosequence bioceramic sealer show promising results as root canal sealer. It exhibited a greater resistance to push out than MTA Fillapex and epoxy resin-based sealers (Adseal) with gutta-percha as a root canal filling.

\section{REFERENCES}

1. Shilder H. Filling root canals in three dimensions. Dent Clin North Am 1967; 11:723-44.

2. King K T, Anderson R W, Pashley D H, Pantera E A. Longitudinal evaluation of the seal of endodontic retro-fillings. J Endod. 1990; 16:307-10. 
3. Miletic I, Anic I, Pezelj-Ribaric S, Jukic S. Leakage of five root canal sealers. Int Endod J. 1999; 32:415-8.

4. Almeida J F, Gomes B P, Ferraz C C, et al. Filling of artificial lateral canals and microleakage and flow of five endodontic sealers. Int Endod J 2007; 40:692-9.

5. Rajput J S, Jain R L, Pathak A. An evaluation of sealing ability of endodontic materials as root canal sealers. J Indian Soc Pedod Prevent Dent 2004; 22:1-7.

6. Cheung W. A review of the management of endodontically treated teeth: post, core and the final restoration. J Am Dent Assoc 2005; 136:611-9.

7. De Cleen M J H. The relationship between the root canal filling and post space preparation. Int Endod J 1993; 26:53-8.

8. Dalat D M, Spangberg L S W. Effect of post preparation on the apical seal of teeth obturated with plastic thermafil obturators. Oral Surg Oral Med Oral Pathol 1993; 76:760-5.

9. Saunders E M, Saunders W P, Rashid M Y A. The effect of post space preparation on the apical seal of root fillings using chemically adhesive materials. Int Endod J 1991; 24:51-7.

10. Schafer E, Zandbiglari T, Schafer J. Influence of resinbased adhesive root canal fillings on the resistance to fracture of endodontically treated roots: an in vitro preliminary study. Oral Surg Oral Med Oral Pathol Oral Radiol Endod 2007; 103:274-9.

11. Onay E O, Ungor M, Ari H, et al. Push-out bond strength and SEM evaluation of new polymeric root canal fillings. Oral Surg Oral Med Oral Pathol Oral Radiol Endod 2009; 107:879-85.

12. Lee K W, Williams M C, Camps J J, Pashley D H. Adhesion of endodontic sealers to dentin and gutta-percha $\mathrm{J}$ Endod, 28 (10) 2002; pp. 684-688.

13. Saleh I M, Ruyter I E, Haapasalo M, Orstavik D.The effects of dentine pretreatment on the adhesion of root-canal sealers Int Endod J, 35 (10) 2002; pp. 859-866.

14. Grossman L I, Endodontic Practice, Henry Kimpton, Philadelphia, Pa, USA, 10th edition, 1981.

15. Zhou H M, Shen Y, Zheng W, Li L, Zheng Y F, and Haapasalo M. "Physical properties of 5 root canal sealers," Endod J 2013; vol. 39, no. 10, pp. 1281-1286.

16. White R R, Goldman M, Lin P S. The influence of the smeared layer upon dentinal tubule penetration by plastic filling materials. Endod J 1984; 10: 558-62.
17. Sen B H, Piskin B, Baran N. The effect of tubular penetration of root canal sealers on dye microleakage. Int Endod J 1996; 29: 23-8.

18. Lalh M S, Titley K, Torneck C D, Friedman S. The shear bond strength of glass ionomer cement sealers to bovine dentine conditioned with common endodontic irrigants. Int Endod J 1999; 32:430-5.

19. Yildirim T, Orucoglu H, Cobankara F K. Long-term evaluation of the influence of smear layer on the apical sealing ability of MTA. Endod J 2008; 34: 1537-40.

20. Grossmann L. Physical properties of root canal cements. Endod J 1976; 2:166-75.

21. Orstavik D. Endodontic materials. Adv Dent Res 1988; 2:12-24.

22. Tronstad L, Barnett F, Flax M. Solubility and biocompatibility of calcium hydroxide-containing root canal sealers. Endod Dent Traumatol 1988; 4:152-9.

23. Weiger R, Heuchert T, Hahn R, Lo“ st C. Adhesion of a glass ionomer cement to human radicular dentine. Endod Dent Traumatol 1995; 11:214-9.

24. Fisher M A, Berzins D W, Bahcall J K. An in vitro comparison of bond strength of various obturation materials to root canal dentin using a push-out test design. Endod $\mathrm{J}$ 2007; 33:856-8.

25. Silva E J, Perez R, Valentim R M, et al. Dissolution, dislocation and dimensional changes of endodontic sealers after a solubility challenge: a micro-CT approach. Int Endod J 2016; Mar 22; http://dx.doi.org/10.1111/iej.12636.

26. De Deus G, Di Giorgi K, Fidel S, et al. Push-out bond strength Resilon/Epiphany

27. and Resilon/Epiphany self-etch to root dentin. Endod J 2009; 35:1048-50.

28. Scarparo R K, Haddad D, Acasigua G A X, Fossati A C M, Fachin E V F, Grecca F S. Mineral trioxide aggregatebased sealer: analysis of tissue reactions to a new endodontic material. Endod J 2010; 36:1174-8.

29. Orosco F A, Bramante C M, Garcia R B, et al. Sealing ability of gray MTA Angelus, CPM and MBPC used as apical plugs. Appl Oral Sci J 2008; 16:50-4.

30. Camilleri J. Modification of MTA: physical and mechanical properties. Int Endod J 2008; 41:843-9.

31. Camilleri J. Evaluation of selected properties of mineral trioxide aggregate sealer cement. Endod J 2009; 35:1412-7. 
32. Silva E J, Rosa T P, Herrera D R, et al. Evaluation of cytotoxicity and physicochemical properties of calcium silicate-based endodontic sealer MTA Fillapex. Endod J 2013; 39:274-7.

33. Han L, Kodama S, Okiji T. Evaluation of calcium-releasing and apatite-forming abilities of fast-setting calcium silicate-based endodontic materials. Int Endod J 2015; 48:124-30.

34. Tay F R, Pashley D H, Rueggerberg F A, et al. Calcium phosphate phase transformation produced by the interaction of the Portland cement component of white mineral trioxide aggregate with a phosphate-containing fluid. En$\operatorname{dod} \mathrm{J} 2007 ; 33: 1347-51$.

35. Reyes-Carmona J F, Felippe M S, Felippe W T. Biomineralization ability and interaction of mineral trioxide aggregate and white Portland cement with dentine in a phosphate containing fluid. Endod J 2009; 35:731-6.

36. Reyes-Carmona J F, Felippe M S, Felippe W T. The biomineralization ability of mineral trioxide aggregate and Portland cement on dentin enhances the push-out strength. Endod J 2010; 36:286-91.

37. Hess D, Solomon E, Spears R, He J. Retreatability of a bioceramic root canal sealing material. Endod J 2011; 37:1547-9.

38. Loushine B A, Bryan T E, Looney S W, et al. Setting properties and cytotoxicity evaluation of a premixed bioceramic root canal sealer. Endod J 2011; 37:673-7.

39. Zhang H, Shen Y, Ruse N D, Haapasalo M. Antibacterial activity of endodontic sealers by modified direct contact test against Enterococcus faecalis. Endod J 2009; 35:1051-5.

40. Gogos C, Economides N, Stavrianos C, Kolokouris I. Adhesion of a new methacrylate resin-based sealer to human dentin Endod J 2004; 30 (4): pp. 238-240

41. Sousa-Neto M D, Silva Coelho F I, Marchesan M A, Alfredo E, Silva-Sousa Y T. Ex vivo study of the adhesion of an epoxy-based sealer to human dentine submitted to irradiation with Er:YAG and Nd:YAG lasers Int Endod J 2005; 38 (12): pp. 866-870.

42. Yavari H, Shahi S, Galledar S, Samiei M, and Janani M. Effect of retreatment on the push-out bond strength of MTA-based and epoxy resin-based endodontic sealers. J Dent Res Dent Clin Dent Prospect 2017; 11(1): 43-47.

43. Shokouhinejad N, Gorjestani H, Nasseh A A, Hoseini A, Mohammadi M, and Shamshiri A R. Push-out bond strength of gutta-percha with a new bioceramic sealer in the presence or absence of smear layer. Aust Endod J 2013; 39: 102-106.

44. DeLong C, He J, Woodmansey K F. The effect of obturation technique on the push-out bond strength of calcium silicate sealers. Endod J 2015; 41:385-8.

45. Gurgel-Filho E D, Martins F. Comparative evaluation of push-out bond strength of a MTA based root canal sealer. Braz J Oral Sci. 2014; 13:114-7.

46. Setia P, Sikri V K, Sroa R B, Sidhu B. Apical sealing ability of two novel root canal sealers: An ex-vivo study. J Int Clin Dent Res Organ. 2013; 5:9-13.

47. Barbizam J V, Trope M, Tanomaru-Filho M, Teixeira E C, Teixeira F B. Bond strength of different endodontic sealers to dentin: Push-out test. J Appl Oral Sci. 2011; 19:644-7.

48. Shokouhinejad N, Hoseini A, Gorjestani H, Shamshiri A $\mathrm{R}$. The effect of different irrigation protocols for smear layer removal on bond strength of a new bioceramic sealer. Iran Endod J. 2013; 8:10-3.

49. Cobankara F K, Ungör M, Belli S. The effect of two different root canal sealers and smear layer on resistance to root fracture. Endod J 2002; 28:606-9.

50. Gade V J, Belsare L D, Patil S, Bhede R, Gade J R. Evaluation of push-out bond strength of endosequence BC sealer with lateral condensation and thermoplasticized technique: An in vitro study. J Conserv Dent. 2015; 18:124-7.

51. Kumar K N, Kumar M P, Rao P S S, Pallavi V, Ahmed S. Comparative Evaluation of Push-out Bond Strength of Novel Smart Seal System with Resilon/Epiphany and Gutta-percha/Ah-plus Obturating System: An in vitro Study Int J Sci Stud 2016; 4(3):114-117.

52. Mahdi AA, Bolaños-Carmona V, Gonzalez-Lopez S. Bond strength to root dentin and fluid filtration test of AH Plus/ gutta-percha, EndoREZ and RealSeal systems. J Appl Oral Sci. 2013; 21:369-75.

53. Koch K, Brave D. Bioceramic technology: the game changer in endodontics. Endodontic Practice 2009; 2:17-21.

54. Huffman B P, Mai S, Pinna L et al. Dislocation resistance of ProRoot Endo Sealer, a calcium silicate-based root canal sealer, from radicular dentine. Int Endod J 2009; 42: 34-46.

55. Vilanova W V, Carvalho-Junior J R, Alfredo E, Sousa-Neto M D, Silva-Sousa Y T. Effect of intracanal irrigants on the bond strength of epoxy resin-based and methacrylate resinbased sealers to root canal walls. Int Endod J 2012; 45:42-8. 
56. Fisher MA, Berzins DW, Bahcall JK. An in vitro compari-son of bond strength of various obturation materials to root canal dentine using a push-out test design. J Endod 2007;33:856-8.

57. Flores D.S., Rached Jr. F.J., Versiani M.A., Guedes D.F., Sousa-Neto M.D., Pecora J.D. Evaluation of physicochemical properties of four root canal sealers Int Endod J, 44 (2) (2011), pp. 126-135

58. Neelakantan P, Grotra D, Sharma S. Retreatability of 2 Mineral Trioxide Aggregate-based Root Canal Sealers: A Cone-beam ComputedTomography Analysis. Endod J 2013; 39:893-6.

59. Borges RP, Sousa-Neto MD, Versiani MA, Rached-Júnior FA, De-Deus G, Miranda CE. et al. Changes in the surface of four calcium silicate-containing endodontic materials and an epoxy resin-based sealer after a solubility test. Int Endod J. 2012;45:419-28.

60. Nagas E, Uyanik MO, Eymirli A, Cehreli ZC, Vallittu PK, Lassila LV, et al. Dentin moisture conditions affect the adhesion of root canal sealers. Endod J 2012; 38:240-4.

61. Assmann E, DDS, Scarparo R K, B€ottcher and Grecca F S. Dentin Bond Strength of Two Mineral Trioxide Aggregate-based and One Epoxy Resin-based Sealers Endod J 2012;38:219-221.

62. Eldeniz AU, Erdemir A, Belli S. Shear bond strength of three resin based sealers to dentin with and without the smear layer. Endod J 2005; 31: 293-6.

63. Gesi A, Raffaelli O, Goracci C, Pashley DH, Tay FR, Ferrari M. Interfacial strength of Resilon and gutta-percha to intraradicular dentin. Endod J 2005; 31: 809-13. 